\title{
Characteristics of acid and pepsin solubilized collagens from Nile tilapia (Oreochromis niloticus) scale
}

\author{
Phanat Kittiphattanabawon $^{1 *}$, Chodsana Sriket ${ }^{2}$, Hideki Kishimura $^{3}$, Soottawat Benjakul ${ }^{4}$ \\ ${ }^{1}$ Department of Food Science and Technology, Faculty of Agro- and Bio-Industry, Thaksin University, Phatthalung Campus, \\ Phatthalung 93210, Thailand, ${ }^{2}$ Program in Food Science and Technology, Faculty of Agriculture, Ubon Ratchathani Rajabhat University, \\ Ubon Ratchathani, 34000, Thailand, ${ }^{3}$ Laboratory of Marine Products and Food Science, Research Faculty of Fisheries Sciences, Hokkaido \\ University, Hakodate, Hokkaido 041-8611, Japan, ${ }^{4}$ Department of Food Technology, Faculty of Agro-Industry, Prince of Songkla University, \\ Hat Yai, Songkhla, 90112, Thailand
}

\section{A B S T R A C T}

\begin{abstract}
In Thailand, the production of tilapia is about 140,000 tons, which is the sixth tilapia production in the world. From the processing, the scale was generated as waste. To produce a value-added product, the production of collagen from tilapia scale could be an alternative. Generally, collagen from fish scale possesses a less fishy odor and flavor than that from fish bone and skin. From the results, the fish scale is an interesting alternative source for collagen extraction. The objectives of this study were to extract collagen from Nile tilapia (Oreochromis niloticus) scale from the production of frozen tilapia fillet as well as to study its properties. Extraction of acid (ASC) and pepsin soluble collagens (PSC) from Nile tilapia scale, as well as the determination of their yield, amino acid compositions, SDS-PAGE patterns, FTIR spectra, thermal denaturation temperature $\left(T_{\max }\right)$ and zeta potential, was conducted. ASC and PSC had a yield of 0.77 and $0.71 \%$ based on dry basis), respectively. The major amino acid found in both collagens was glycine (322-332 residues/1000 residues). Also, they had a high amount of imino acid (199-205 residues/1000 residues). Based on SDS-PAGE pattern, both collagens were classified as type I collagen $\left((\alpha 1)_{2} \alpha 2\right.$-heterotrimer). The similar FTIR spectra of both collagens were found. Their amide peaks had no shift in wavenumber. ASC and PSC had $T_{\max }$ of 36.15 and $34.70{ }^{\circ} \mathrm{C}$, respectively. From zeta potential analysis, ASC and PSC had the zero of net chart at pH 5.09 and 5.84, respectively. Based on the characteristics of the collagen, the scale could be an alternative source for collagen production, however their yield should be improved to serve as a potential source for further application.
\end{abstract}

Keywords: Acid soluble collagen; Collagen; Nile tilapia; Pepsin soluble collagen; Scale

\section{INTRODUCTION}

Tilapia is a freshwater fish, which is one-third of the most aquaculture fish in the world (Mohammad et al., 2014). It is also a popular fish for consumption because its meat is mild flavor and white (Yongsawatdigul et al., 2000). In Thailand, production of tilapia is about 140,000 tons, which is the world's sixth tilapia production in the world. The twentythree percent of them was processed as tilapia fillets. From the processing, the scales were generated as waste about $2 \%$ of them, which was estimated to be 700 tons (Noorit, 2017). Generally, tilapia scales were discarded as waste or fertilizer, which are low market value. The production of collagen from tilapia scale could add the value of the scale.

Collagen is a connective tissue, which found in skin, hair, tendon, bone, and scale. It has been normally applied in various industries, including pharmaceutical, medical, photographic, and food (Benjakul et al., 2012; Foegeding et al., 1996). For the collagen production, the bone and skin from porcine and bovine generally are the main source due to Muslim, Jew, and Hindu cannot consume those collagens. The choice of source for collagen production, especially from fish processing by-products, including bone, skin, and scale, have gained attention as noticed by the increasing of research related to collagen extraction from fish by-products a decade ago (Chen et al., 2016; Chuaychan et al., 2015; Duan et al., 2009; Kittiphattanabawon et al., 2015; Liu et al., 2012; Matmaroh et al., 2011; Minh Thuy et al., 2014; Savedboworn et al., 2017; Sinthusamran et al., 2013). Most of the fish collagens were extracted from the skin because of the high yield obtained. However, fish skin collagen had undesirable fish odor and flavor due to fish skin contained phospholipid as a major component, which is prone to

\footnotetext{
*Corresponding author:

Phanat Kittiphattanabawon, Department of Food Science and Technology, Faculty of Agro- and Bio-Industry, Thaksin University, Phatthalung Campus, Phatthalung 93210, Thailand. Tel: 66-7460-9600 ext. 3319. Fax: 66-7460-9618. E-mail: phanat@scholar.tsu.ac.th

Received: 01 January 2019; Accepted: 06 February 2019
} 
oxidation (Sae-leaw et al., 2013). This is a limitation of its application. Sae-Leaw et al. (2015) had diminished the fishy odor and flavor by pretreatment with citric acid and spray drying to remove membrane lipid and volatile some fishy odor during the drying process, respectively. However, the process could not completely remove the fishy odor and flavor. Generally, a fish scale collagen has a less fishy odor and flavor than collagen from fish bone and skin due to it had a trace amount of lipid (Huang et al., 2016). From the results, the fish scale is an interesting alternative source for collagen extraction, although its yield is quite lower when compared with collagen from fish skin. Recently, collagen extraction from fish scale obtained from fish different species, such as seabass, lizard fish, grey mullet, spotted golden goatfish, flying fish, horse mackerel, yellowback seabream, and grass carp had been studied (Chuaychan et al., 2015; Matmaroh et al., 2011; Minh Thuy et al., 2014; Wang et al., 2014). Nevertheless, a little information about collagen extraction from Nile tilapia scale had been accounted. Therefore, the objectives of this research were to extract Nile tilapia (Oreochromis niloticus) scale collagen, which obtained from the production of frozen tilapia fillet as well as to study its characteristics.

\section{MATERIALS AND METHODS}

\section{Chemicals}

All chemicals used were analytical grade. The protein markers and chemicals for electrophoresis were ordered from GE Healthcare UK Limited (Buckinghamshire, UK) and Bio-Rad Laboratories (Hercules, CA, USA), respectively. Porcine stomach mucosa pepsin (EC 3.4.23.1) and calf skin type I collagen were purchased from Sigma Chemical Co. (St. Louis, MO, USA).

\section{Preparation of tilapia scale}

0.4-0.6 kg/piece of fresh tilapia (Oreochromis niloticus) was collected from a local tilapia processing plant in Songkhla, Thailand. The preparation of the scale was proceeded by the method of Chuaychan et al. (2015). Briefly, the obtained scale was washed, drained, packed into a polyethylene bag, frozen and kept below $-18^{\circ} \mathrm{C}$. The frozen storage was not more than 6 months. The prepared scale had the moisture content of $76.21 \%$ as determined by the gravimetric method AOAC (2000). Before the collagen extraction, running water was used for thawing the frozen scale until its core temperature of $8-10^{\circ} \mathrm{C}$ was reached.

\section{Extraction of tilapia scale collagen}

Collagen from the tilapia scale was extracted as the slightly modified method of (Chuaychan et al., 2015). The temperature of all procedures was controlled below $10^{\circ} \mathrm{C}$. Briefly, the non-collagenous protein was eliminated by mixing with $0.1 \mathrm{M} \mathrm{NaOH}$ for $6 \mathrm{~h}$. The minerals were eliminated from the pretreated scale by mixing the scale in $0.5 \mathrm{M}$ EDTA-2Na ( $\mathrm{pH} 7.4$ ) for $48 \mathrm{~h}$. The demineralized scale was immersed in $0.5 \mathrm{M}$ acetic acid for $72 \mathrm{~h}$, followed by filtration, salt precipitation at $\mathrm{pH} 7.5(2.6 \mathrm{M} \mathrm{NaCl}$ containing 0.05 M Tris(hydroxymethyl) aminomethane), centrifugation, dissolving the precipitate obtained, dialysis and freeze drying. The solid/solution ratio used in those processes were 1:10, 1:10 and 1:15 (w/v), respectively.

To extract pepsin soluble collagen, a parts of the undissolved residue was subjected to immerse in 10 parts of $0.5 \mathrm{M}$ acetic acid containing 20 unit/g of porcine pepsin for $72 \mathrm{~h}$. To recovery the collagen, the mixture was conducted as the method described above. The resulting collagen from acid and pepsin solubilization processes were referred to as "acid (ASC) and pepsin soluble collagen (PSC)", respectively.

\section{Yield of collagen from tilapia scale}

The yield calculation was conducted as the following equation:

Yield $(\%)=$

$$
\begin{aligned}
& \text { Hyp content in collagen } \\
& \frac{(\mathrm{mg} / \mathrm{g} \text { gelatin }) \text { x collagen obtained }(\mathrm{g})}{\text { Hyp content in scale }(\mathrm{mg} / \mathrm{g} \text { skin })} \times 100 \\
& \mathrm{x} \text { scale used for extraction }(\mathrm{g})
\end{aligned}
$$

Hydroxyproline (Hyp) content in the scale and collagen were determined by spectrophotometric method, which was improved and simplified by Bergman and Loxley (1963).

\section{Characterization of collagen from the tilapia scale Amino acid analysis}

ASC and PSC were hydrolyzed under reduced pressure in $4.0 \mathrm{M}$ methane sulphonic acid containing $0.2 \%(\mathrm{v} / \mathrm{v})$ 3 -2(2-aminoethyl)indole at $115^{\circ} \mathrm{C}$ for $24 \mathrm{hr}$. The hydrolysates were neutralized with $3.5 \mathrm{M} \mathrm{NaOH}$ and diluted with $0.2 \mathrm{M}$ citrate buffer ( $\mathrm{pH}$ 2.2). The neutralized sample $(0.4 \mathrm{~mL})$ was subjected to an amino acid analyzer (MLC-703; Atto Co., Tokyo, Japan).

SDS-polyacrylamide gel electrophoresis (SDS-PAGE) SDS-PAGE was conducted as described by Laemmli (1970). The samples, which were prepared under non-reducing and reducing conditions as described by Kittiphattanabawon et al. (2010), were loaded onto a polyacrylamide gel (4\% stacking gel and $7.5 \%$ separating gel) along with the protein marker and calf skin type I collagen for estimation the molecular weight of protein and using as a standard collagen, respectively. The Image (Image J 1.42q, National Institutes of Health, Bethesda, MD, USA) was used to 
quantify the band intensity.

\section{Fourier transform infrared (FTIR) spectroscopy}

A Bruker model EQUINOX 55 FTIR spectrometer (Bruker, Ettlingen, Germany) was used for evaluation the FTIR spectra of both collagens as described by Kittiphattanabawon et al. (2010). A DLATGS (deuterated l-alanine tri-glycine sulphate) was used as the detector. The setting condition for evaluation the spectra included $4 \mathrm{~cm}^{-1}$ of the resolution, the measurement range of mid-IR region (4000- $\left.650 \mathrm{~cm}^{-1}\right), 32$ scans of the automatic signals collection and measurement temperature of $25^{\circ} \mathrm{C}$. An OPUS 3.0 data collection program (Bruker, Ettlingen, Germany) was used the software for analysis of spectral data.

\section{Differential scanning calorimetry (DSC)}

To rehydrate the collagen, $1 \mathrm{~mL}$ of deionized water was added into $250 \mathrm{mg}$ of collagen. The mixtures incubated at $4{ }^{\circ} \mathrm{C}$ for 2 days before analysis. The DSC thermogram of collagen was determined by the DSC 7 (Perkin Elmer, Norwalk, CT, USA), following the method of Kittiphattanabawon et al. (2010). The sample was heated from 25 to $50{ }^{\circ} \mathrm{C}$ with heating rate of $1{ }^{\circ} \mathrm{C} / \mathrm{min}$. The maximum transition temperature $\left(T_{\max }\right)$ and total denaturation enthalpy $(\Delta H)$ was estimated from DSC thermogram.

\section{Zeta potential analysis}

Zeta (乌) potential of $0.05 \%(\mathrm{w} / \mathrm{v})$ collagen solutions, which prepared by dissolving in $0.5 \mathrm{M}$ acetic acid, was measured by the ZetaPALs (Brookhaven Instruments Co., Holtsville, NY, USA) according to the method of Kittiphattanabawon et al. (2010).

\section{Statistical analysis}

The experiments were proceeded in triplicate using three different lots of samples. The difference between means were tested by T-test (Steel and Torrie, 1980).

\section{RESULTS AND DISCUSSIONS}

\section{Yield of collagen}

Extraction of ASC and PSC from Nile tilapia scale gave yields of 0.77 and $0.71 \%$ based on hydroxyproline content, respectively. The recovery of total collagen (ASC and PSC) was $1.48 \%$, which was much lower than with that of collagens from different fish skins, clown featherback (82.1\%), rohu $(82.5 \%)$ (Kittiphattanabawon et al., 2015; Savedboworn et al., 2017). It was possibly due to the fish scales were biocomposites of highly ordered type I collagen fibers with hydroxyapatite $\left(\mathrm{Ca}_{5}\left(\mathrm{PO}_{4}\right)_{3} \mathrm{OH}\right)$ and several cross-linked regions (Zylberberg et al., 1988). However, the yield was comparable with collagen from the different scales, spotted golden goatfish $(1.66 \%)$, seabass $(1.44 \%)$ and golden carp
(1.58\%) (Ali et al., 2017; Chuaychan et al., 2015; Matmaroh et al., 2011). The yield might be enhanced by ultrasound assisted extraction via due to mechanical and cavitation effect of ultrasound (Ali et al., 2018; Song et al., 2018; Tu et al., 2015). Song et al. (2018) reported that the ultrasound assisted extraction could enhanced the yield of collagen by 1.5-2 times of that obtained by conventional extraction.

\section{Amino acid compositions}

According to Table 1, both ASC and PSC had glycine (322332 residues / 1000 residues), alanine (114-124 residues $/ 1000$ residues), proline (114-119 residues/1000 residues) and hydroxyproline (85-86 residues /1000 residues) as the major amino acid with low amount of phenylalanine (13-14 residues / 1000 residues), methionine (10-11 residues $/ 1000$ residues), isoleucine (9-14 residues/1000 residues) hydroxylysine (7-9 residues/1000 residues), histidine (6-8 residues $/ 1000$ residues), tyrosine (4-6 residues $/ 1000$ residues) and cysteine (1 residue/1000 residues). The result was in agreement with amino acid composition of type I collagen from other sources (Ali et al., 2018; Chuaychan et al., 2015; Huang et al., 2016; Savedboworn et al., 2017). Glycine content was about $1 / 3$ of total amino acid, which is normally found in collagen. It located on every third position of peptide chain of collagen molecule, excepted at telopeptide region which is the chain located at the first 14 and 10 amino acid residues from $\mathrm{N}$ - and C-terminus, respectively (Foegeding et al., 1996; Kittiphattanabawon et al., 2005). The imino acid content of both collagens was 199-205 residues/1000 residues, which was higher than that of the scale collagens of seabass (193-195 residues/1000

Table 1: Amino acid compositions of ASC and PSC from the scale of tilapia (residues/1000 residues)

\begin{tabular}{lcc}
\hline Amino acid & ASC & PSC \\
\hline Alanine & 124 & 114 \\
Arginine & 52 & 48 \\
Aspartic acid/Asparagine & 43 & 44 \\
Cysteine & 1 & 1 \\
Glutamine/Glutamic acid & 68 & 69 \\
Glycine & 332 & 322 \\
Histidine & 6 & 8 \\
Isoleucine & 9 & 14 \\
Leucine & 23 & 26 \\
Lysine & 25 & 24 \\
Hydroxylysine & 7 & 9 \\
Methionine & 10 & 11 \\
Phenylalanine & 13 & 14 \\
Hydroxyproline & 86 & 85 \\
Proline & 119 & 114 \\
Serine & 37 & 42 \\
Threonine & 23 & 28 \\
Tyrosine & 4 & 6 \\
Valine & 18 & 21 \\
Total & 1000 & 1000 \\
Imino acid & 205 & 199 \\
\hline
\end{tabular}


residues), carp (192 residues/1000 residues), bighead carp (156 residues/1000 residues) and golden carp (Ali et al., 2017; Chuaychan et al., 2015; Duan et al., 2009; Liu et al., 2012). The imino acid content, which associates environment temperature of animal habitat and thermal stability of collagen, plays an essential role in gel strength and rheological property (Benjakul et al., 2012; Foegeding et al., 1996). Regenstein and Zhou (2007) reported that imino acid is a key factor determining their potential use. Negligible differences were found between amino acid composition of ASC and PSC. It was possibly due to removal of some portion of telepeptides hydrolyzed by pepsin.

\section{SDS-PAGE patterns}

Generally, SDS-PAGE patterns of ASC and PSC were quite same, but there was slight difference in MW of $\alpha 1$ and $\alpha 2$. Both chains of PSC had slightly lower MW, when compared with those of ASC and $\beta$-chain of PSC had less band intensity when compared with that of ASC (Fig.1). Chuaychan et al. (2015) reported that some part of telopeptide region, especially crosslinked components, could be remove by pepsin as seen by lower band intensity in $\beta$-chain of PSC. When comparing SDS-PAGE patterns of ASC and PSC under reducing and non-reducing conditions, no difference was found. The result suggests that there was no di-sulfide bond formation in both collagens. It well correlated with low content of cysteine as shown in Table 1. In both collagens, the $\beta$-, $\alpha 1$ - and $\alpha 2$ - chains were found as the major components along with low amount of $\gamma$-chain. The band intensity of $\alpha 1$ was approximately 2 times of $\alpha 2$, suggesting that tilapia scale collagen was characterized as type I collagen. The result was in agreement with protein patterns of collagen from the other fish scales, seabass, golden carp, red drum fish, grey mullet, horse mackerel, lizard fish and yellowback seabream (Ali et al., 2017; Chen et al., 2016; Chuaychan et al., 2015; Minh Thuy et al., 2014).

\section{Fourier transform infrared (FTIR) spectra}

Generally, FTIR spectra of any protein include peaks of amide A, B, I, II and III. The amide A and B associate with the vibrations of $\mathrm{N}-\mathrm{H}$ stretching or the presence of hydrogen bond and asymmetrical $\mathrm{CH}_{2}$ stretching, respectively (Abe and Krimm, 1972; Doyle et al., 1975). The amide I, II and III relate with hydrogen bond coupled with $\mathrm{COO}^{-}$or stretching vibration of $\mathrm{C}=\mathrm{O}$, bending vibration of $\mathrm{N}-\mathrm{H}$ coupled with stretching vibration of $\mathrm{C}-\mathrm{N}$ and stretching vibration of $\mathrm{C}-\mathrm{N}$ and/or deformation of $\mathrm{N}-\mathrm{H}$, respectively (Krimm and Bandekar, 1986; Muyonga et al., 2004; Payne and Veis, 1988). The FTIR spectra of both collagens shown in Fig. 2 included amide A $\left(3292-3296 \mathrm{~cm}^{-1}\right)$, amide B $\left(2922-2924 \mathrm{~cm}^{-1}\right)$, amide I $\left(1637-1639 \mathrm{~cm}^{-1}\right)$, amide II $\left(1539-1540 \mathrm{~cm}^{-1}\right)$ and amide III $\left(1234-1236 \mathrm{~cm}^{-1}\right)$. The wavenumber of each peak in the FTIR spectra were slightly different when compared with the FTIR spectra of collagen from spotted golden goatfish and seabass scales (Chuaychan et al., 2015; Matmaroh et al., 2011). No shift in wavenumber of amide I and II between ASC (1637 and $1639 \mathrm{~cm}^{-1}$, respectively) and PSC (1539 and $1540 \mathrm{~cm}^{-1}$, respectively) was found $(\mathrm{P}<0.05)$.

All peaks in the FTIR spectra between ASC and PSC had no shift in wavenumber $(\mathrm{P}>0.05)$, indicating that no difference in secondary structure between both collagens and hydrolysis of pepsin during extraction did not affect to the structure. The results were confirmed by two main evidences. Firstly, the triple helical alignment of both collagens was same as indicated by no shift in wavenumber of amide I and II of both collagens. Payne and Veis (1988) reported that an amide I and II shifts to lower wavenumber relates with a lessening in the molecular order. Secondly, the existence of triple helical structure of both collagens, as indicated by the absorbance ratios of amide III/1454 $\mathrm{cm}^{-1}$ of ASC (0.99) and PSC (1.01) were approximately 1.0.

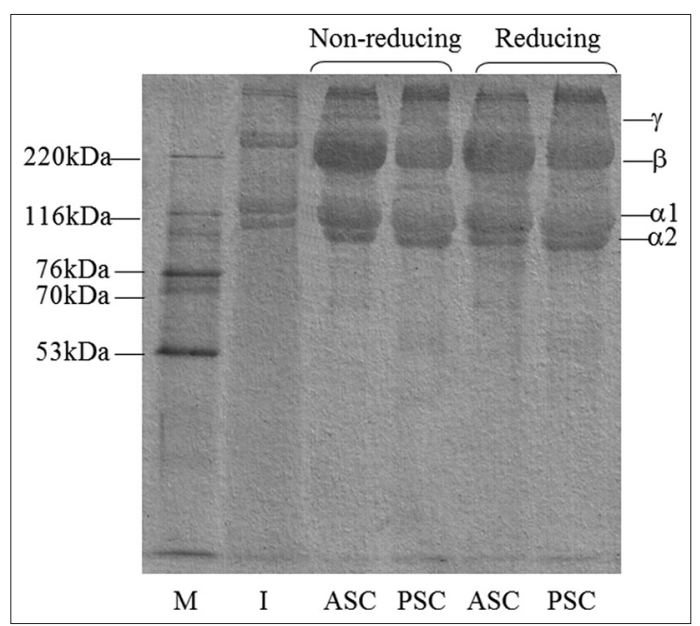

Fig 1. Protein patterns of ASC and PSC from tilapia scale under non-reducing and reducing conditions. $\mathrm{M}$ and I denote high molecular weight protein markers, and type I collagen from calf skin, respectively.

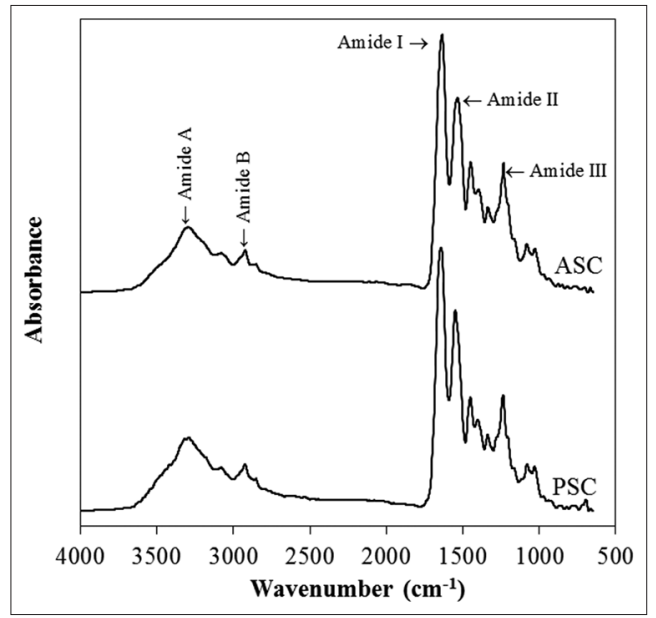

Fig 2. FTIR spectra of ASC and PSC from tilapia scale. 
Plepis et al. (1996) reported that the ratio of 1.0 shows the existence of the triple helical structure.

\section{Thermal transition temperature $\left(T_{\max }\right)$}

$T_{\max }$ and enthalpy $(\Delta H)$ of both collagens obtained from the endothermic peak in DSC thermograms as shown in Fig. 3. $T_{\max }\left(36.15^{\circ} \mathrm{C}\right)$ and $\Delta H(1.23 \mathrm{~J} / \mathrm{g})$ of ASC were higher than those of PSC $\left(34.70{ }^{\circ} \mathrm{C}\right.$ and $0.76 \mathrm{~J} / \mathrm{g}$, respectively). $T_{\max }$ of both collagens were coincidental with their imino acid content (Table 1). The helical structure of collagen was stabilized by the imino acid (Benjakul et al., 2012; Ikoma et al., 2003). $T_{\max }$ of collagen from tilapia scale was comparable to grass carp $\left(34.8-35.2^{\circ} \mathrm{C}\right.$ ) (Wang et al., 2014). However, they were quite lower than that of collagen from different fish scales, golden carp $\left(37.67-37.83^{\circ} \mathrm{C}\right)$, seabass $\left(38.17-39.32{ }^{\circ} \mathrm{C}\right)$ and spotted golden goatfish $\left(41.01-41.58^{\circ} \mathrm{C}\right)$ and much higher than that of collagen from the different scales, lizard fish $\left(27.4-27.6{ }^{\circ} \mathrm{C}\right)$, horse mackerel $\left(26.1-28.1^{\circ} \mathrm{C}\right)$ and carp $\left(28^{\circ} \mathrm{C}\right)$ (Ali et al., 2017; Chuaychan et al., 2015; Duan et al., 2009; Matmaroh et al.,

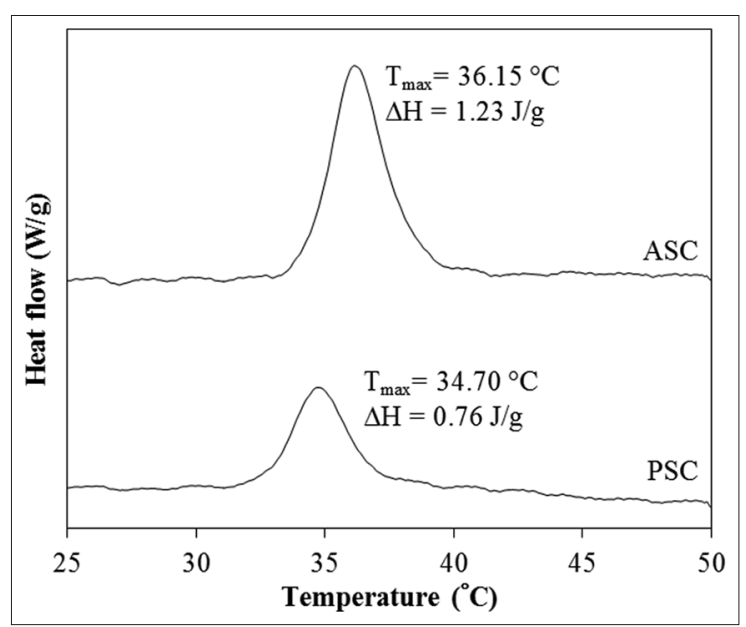

Fig 3. DSC thermograms of ASC and PSC from tilapia scale.

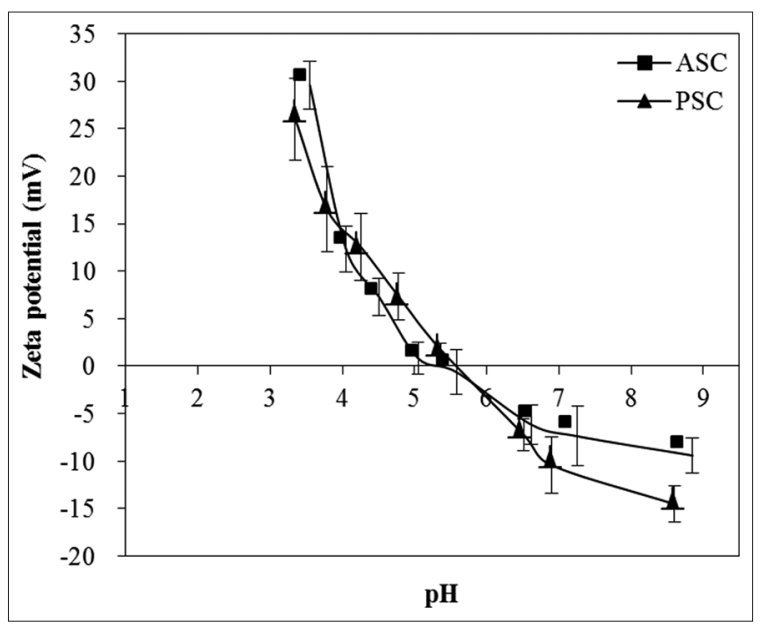

Fig 4. Zeta potentials of ASC and PSC from tilapia scale at different $\mathrm{pHs}$. Bars represent the standard deviation $(n=5)$.
2011; Minh Thuy et al., 2014). The difference in $T_{\max }$ among fish species was possible to be from the difference in their imino acid content, normal habitat and body temperatures, amino acid sequence and the conformation of collagen (Foegeding et al., 1996; Sinthusamran et al., 2013). Benjakul et al. (2010) reported that the higher thermal stability of collagen depended on imino acid content, which contained pyrrolidine rings, were able to form hydrogen bond through the hydroxyl group of hydroxyproline. As the lowered in $\Delta H$ of PSC, it suggests that the peptide at telopeptide region cleaved by pepsin might contribute to the thermal denaturation of PSC (Kittiphattanabawon et al., 2010).

\section{Zeta potential}

The changes of surface net charge of both collagens at different $\mathrm{pHs}$ was described by their Zeta potential (Fig. 4). Sharp decrease in zeta potential of ASC and PSC was found at $\mathrm{pH}$ ranging from 3-6.5. The reduction rate in zeta potential of ASC was higher and lower than that of PSC as $\mathrm{pH}$ increased from 3-6.5 and higher than 6.5, respectively. ASC had the zero of net charge at $\mathrm{pH} 5.09$, while PSC was at 5.84. A protein shows a net negative and positive charges as at $\mathrm{pH}$ above and below their isoelectric point ( $\mathrm{pI}$ ), respectively, which caused by protonation and deprotonation of amino acids, respectively (Benjakul et al., 2010; Damodaran, 1996). From the results, it could be assumed that pI of ASC and PSC was 5.09 and 5.84, respectively. The pI of collagen from other fish scale as determined by zeta potential had been reported that it was in faintly acidic to neutral $\mathrm{pH}$. The pI of ASC and PSC of seabass was 4.95 and 5.76, respectively, while that of golden carp was 6.04 and 6.22 , respectively (Ali et al., 2017; Chuaychan et al., 2015). The difference in the $\mathrm{pI}$ among fish collagens might by cause by the difference in their distribution of amino acid residues and amino acid compositions among fish species (Ali et al., 2017). Additionally, the difference in zeta potential profile between both collagens was possibly from their amino acid composition had some differences (Table 1).

\section{CONCLUSIONS}

Collagen could be extracted from the scale of Nile tilapia, which classified as type I collagen. However, low recovery of total collagen $(1.48 \%)$ was observed. Use of pepsin could increase yield about $92.22 \%$. According to protein pattern, $T_{\max }$ and FTIR spectra analyses, the removal of peptide at telopeptide region cleaved by pepsin had no effect on the triple helical structure. Based on their yield and characteristics, use of pepsin could improve yield of the collagen without any impact on its triple helical structure as well as the scale could be an alternative source for collagen production, however yield improvement of the collagen should be further studied to increase the potential used of the scale. 


\section{ACKNOWLEDGEMENTS}

This work was funded by Thaksin University Research Fund for contract No. 2560A10502009 to Dr. Phanat Kittiphattanabawon. The authors would like to acknowledge Faculty of Agro-industry, Prince of Songkla University for the support the instruments used in this research.

\section{Authors' contributions}

Phanat Kittiphattanabawon designed and proceeded the experiment, analyzed, interpreted and concluded the result. Chodsana Sriket and Hideki Kishimura analyzed the SDSPAGE patterns and amino acid composition, respectively. Soottawat Benjakul supported instrument for analysis and gave a suggestion for experimental design and results discussion.

\section{REFERENCES}

Abe, Y. and S. Krimm. 1972. Normal vibrations of crystalline polyglycine I. Biopolymers. 11: 1817-1839.

Ali, A. M. M., S. Benjakul and H. Kishimura. 2017. Molecular characteristics of acid and pepsin soluble collagens from the scales of golden carp (Probarbus jullieni). Emirates J Food Agric. 29: 450-457.

Ali, A. M. M., H. Kishimura and S. Benjakul. 2018. Extraction efficiency and characteristics of acid and pepsin soluble collagens from the skin of golden carp (Probarbus Jullieni) as affected by ultrasonication. Process Biochem. 66: 237-244.

AOAC. 2000. Official Methods of Analysis. $17^{\text {th }}$ ed. Association of Official Ananlytical Chemists Inc., Arlington, VA.

Benjakul, S., S. Nalinanon and F. Shahidi. 2012. Fish collagen. In: Simpson, B. K., G. Paliyath, L. M. L. Nollet, S. Benjakul and F. Toldrá, editors. Food Biochemistry and Food Processing. John Wiley and Sons, Inc., lowa, pp. 365-387.

Benjakul, S., Y. Thiansilakul, W. Visessanguan, S. Roytrakul, H. Kishimura, T. Prodpran and J. Meesane. 2010. Extraction and characterisation of pepsin-solubilised collagens from the skin of bigeye snapper (Priacanthus tayenus and Priacanthus macracanthus). J. Sci. Food Agric. 90: 132-138.

Bergman, I. and R. Loxley. 1963. Two improved and simplified methods for the spectrophotometric determination of hydroxyproline. Anal. Chem. 35: 1961-1965.

Chen, S., H. Chen, Q. Xie, B. Hong, J. Chen, F. Hua, K. Bai, J. He, R. Yi and H. Wu. 2016. Rapid isolation of high purity pepsin-soluble Type I collagen from scales of red drum fish (Sciaenops ocellatus). Food Hydrocoll. 52: 468-477.

Chuaychan, S., S. Benjakul and H. Kishimura. 2015. Characteristics of acid-and pepsin-soluble collagens from scale of seabass (Lates calcarifer). LWT Food Sci. Technol. 63: 71-76.

Damodaran, S. 1996. Amino acids, peptides, and proteins. In: Fennema, O. R., editor. Food Chemistry. Marcel Dekker, Inc., New York, pp. 321-429.

Doyle, B. B., E. R. Blout and E. G. Bendit. 1975. Infrared spectroscopy of collagen and collagen like polypeptides. Biopolymers. 14: 937-957.

Duan, R., J. Zhang, X. Du, X. Yao and K. Konno. 2009. Properties of collagen from skin, scale and bone of carp (Cyprinus carpio). Food Chem. 112: 702-706.
Foegeding, E. A., T. C. Lanier and H. O. Hultin. 1996. Characteristics of edible muscle tissues. In: Fennema, O. R., editor. Food Chemistry. Marcel Dekker, Inc., New York, pp. 879-942.

Huang, C. Y., J. M. Kuo, S. J. Wu and H. T. Tsai. 2016. Isolation and characterization of fish scale collagen from tilapia (Oreochromis $\mathrm{sp}$.) by a novel extrusion-hydro-extraction process. Food Chem. 190: 997-1006.

Ikoma, T., H. Kobayashi, J. Tanaka, D. Walsh and S. Mann. 2003. Physical properties of Type I collagen extracted from fish scales of Pagrus major and Oreochromis niloticas. Int. J. Biol. Macromol. 32: 199-204.

Kittiphattanabawon, P., S. Benjakul, S. Sinthusamran and $\mathrm{H}$. Kishimura. 2015. Characteristics of collagen from the skin of clown featherback (Chitala ornata). Int. J. Food Sci. Technol. 50: 1972-1978.

Kittiphattanabawon, P., S. Benjakul, W. Visessanguan, H. Kishimura and F. Shahidi. 2010. Isolation and characterisation of collagen from the skin of brownbanded bamboo shark (Chiloscyllium punctatum). Food Chem. 119: 1519-1526.

Kittiphattanabawon, P., S. Benjakul, W. Visessanguan, T. Nagai and M. Tanaka. 2005. Characterisation of acid-soluble collagen from skin and bone of bigeye snapper (Priacanthus tayenus). Food Chem. 89: 363-372.

Krimm, S. and J. Bandekar. 1986. Vibrational spectroscopy and conformation of peptides, polypeptides, and proteins. Adv. Protein Chem. 38: 181-364.

Laemmli, U. K. 1970. Cleavage of structural proteins during the assembly of the head of bacteriophage T4. Nature. 227: 680-685.

Liu, D., L. Liang, J. M. Regenstein and P. Zhou. 2012. Extraction and characterisation of pepsin-solubilised collagen from fins, scales, skins, bones and swim bladders of bighead carp (Hypophthalmichthys nobilis). Food Chem. 133: 1441-1448.

Matmaroh, K., S. Benjakul, T. Prodpran, A. B. Encarnacion and H. Kishimura. 2011. Characteristics of acid soluble collagen and pepsin soluble collagen from scale of spotted golden goatfish (Parupeneus heptacanthus). Food Chem. 129: 1179-1186.

Minh, T. L. T., E. Okazaki and K. Osako. 2014. Isolation and characterization of acid-soluble collagen from the scales of marine fishes from Japan and Vietnam. Food Chem. 149: 264-270.

Mohammad, A. W., A. G. Kumar and R. K. Basha. 2014. Optimization of enzymatic hydrolysis of tilapia (Oreochromis Spp.) scale gelatine. Int. Aquat. Res. 7: 27-39.

Muyonga, J. H., C. G. B. Cole and K. G. Duodu. 2004. Fourier transform infrared (FTIR) spectroscopic study of acid soluble collagen and gelatin from skins and bones of young and adult Nile perch (Lates niloticus). Food Chem. 86: 325-332.

Noorit, K. 2017. Nile Tilapia Situation and its Products Report 2013. Available from: http://www.fishco.fisheries.go.th/pages/fish\%20 tilapia.html\#. [Last retrieved on 2017 Jun 16].

Payne, K. J. and A. Veis. 1988. Fourier transform IR spectroscopy of collagen and gelatin solutions: Deconvolution of the amide I band for conformational studies. Biopolymers. 27: 1749-1760.

Plepis, A. M. D., G. Goissis and D. K. Das-Gupta. 1996. Dielectric and pyroelectric characterization of anionic and native collagen. Polym. Eng. Sci. 36: 2932-2938.

Regenstein, J. M. and P. Zhou. 2007. Collagen and gelatin from marine by-products. In: Shahidi, F., editor. Maximising the Value of Marine By-Products. Woodhead Publishing Limited, Cambridge, pp. 279-303.

Sae-Leaw, T., S. Benjakul, N. Gokoglu and S. Nalinanon. 2013. Changes in lipids and fishy odour development in skin from Nile 
tilapia (Oreochromis niloticus) stored in ice. Food Chem. 141: 2466-2472.

Sae-Leaw, T., S. Benjakul and N. M. O'Brien. 2015. Effect of pretreatments and drying methods on the properties and fishy odor/flavor of gelatin from seabass (Lates calcarifer) skin. Drying Technol. 34: 1-13.

Savedboworn, W., P. Kittiphattanabawon, S. Benjakul, S. Sinthusamran and H. Kishimura. 2017. Characteristics of Collagen from Rohu (Labeo rohita) Skin. J. Aquat. Food Prod. Technol. 26: 248-257.

Sinthusamran, S., S. Benjakul and H. Kishimura. 2013. Comparative study on molecular characteristics of acid soluble collagens from skin and swim bladder of seabass (Lates calcarifer). Food Chem. 138: 2435-2441.

Song, K. M., S. K. Jung, Y. H. Kim, Y. E. Kim, and N. H. Lee. 2018. Development of industrial ultrasound system for mass production of collagen and biochemical characteristics of extracted collagen. Food Bioprod. Process. 110: 96-103.
Steel, R. G. D. and J. H. Torrie. 1980. Principles and Procedures of Statistics: A Biometrical Approach. $2^{\text {nd }}$ ed. McGraw-Hill, New York.

Tu, Z. C., T. Huang, H. Wang, X. M. Sha, Y. Shi, X. Q. Huang, Z. Z. Man and D. J. Li. 2015. Physico-chemical properties of gelatin from bighead carp (Hypophthalmichthys nobilis) scales by ultrasoundassisted extraction. J. Food Sci. Technol. 52: 2166-2174.

Wang, H., Y. Liang, H. Zhang, M. Wang and L. Liu. 2014. Physicalchemical properties of collagens from skin, scale, and bone of grass carp (Ctenopharyngodon idellus). J. Aquat. Food Prod. Technol. 23: 264-277.

Yongsawatdigul, J., J. W. Park, P. Virulhakul and S. Viratchakul. 2000. Proteolytic degradation of tropical tilapia surimi. J. Food Sci. 65: 129-133.

Zylberberg, L., J. Bereiter-Hahn and J. Y. Sire. 1988. Cytoskeletal organization and collagen orientation in the fish scales. Cell Tissue Res. 253: 597-607. 